\title{
Evaluation of Humoral and Cell Mediated Immune Response of Sheep Vaccinated with an Inactivated Trivalent FMD Vaccine Adjuvant with Montanide ISA 201
}

G.F.El-Bagoury ${ }^{1}$, A.S.El-Habbaa ${ }^{1}$, H.A.M.Baiomy ${ }^{2}$, and H.M.El-Watany ${ }^{2}$

${ }^{1}$ Virology Dept ., Faculty of Veterinary Medicine, Benha Univ., Benha, Egypt

${ }^{2}$ Foot and Mouth Disease Vaccine Research Dept.,Veterinary Serum and Vaccine Research Institute, Abbasia, Cairo, Egypt. E-Mail: AYMAN.EL-HBBAK@fvtm.bu.edu.eg

\begin{abstract}
Foot and mouth disease (FMD) is a contagious disease of cloven-hoofed animals including cattle, buffaloes, sheep, goats and pigs with economic impact due to losses of production, reduced milk yield and abortion. Control of FMD is widely depending on vaccination. This work aimed to evaluate an inactivated trivalent FMD vaccine prepared using Montanide ISA 201 adjuvant applied in sheep. The prepared vaccine was sterile, safe and induced protective neutralizing antibody titer from the second week post vaccination (wPV), reached the highest level at $12^{\text {th }} \mathrm{wPV}$ and persisted in protective level till $40 \mathrm{wPV}$ for FMD virus serotypes O, A and SAT2. These results were confirmed using ELISA. Evaluation of FMD virus-specific cell-mediated immunity in sheep vaccinated using XTT assay showed a high lymphocyte proliferation expressed by optical density in vaccinated sheep group from the $3^{\text {rd }}$ day post vaccination (dPV), increased to reach a maximum value $2^{\text {nd }}$ wPV and persisted in a high level till $9^{\text {th }}$ wPV for FMDV types O, A and SAT2 inducers. It was concluded that the prepared inactivated trivalent FMD vaccine with ISA-201 adjuvant induced good humoral and cellular immune responses in sheep lasted for $40 \mathrm{wPV}$.
\end{abstract}

Keywords: FMD Vaccine, ISA 201, Sheep, SNT, ELISA, XTT Assay.

\section{Introduction}

Foot and mouth disease (FMD) is a contagious disease of cloven-hoofed animals including cattle, buffaloes, sheep, goats and pigs. It has an important economic impact in livestock causing losses of production, reduced milk yield, abortion, and prenatal mortalities [20]. FMD virus belonged to genus Aphthovirus of the family Picornaviridae, has a positive sense -single stranded RNA genome and occurs in seven distinct serotypes (A, C, O, Asia 1, and SAT 1-3) [3]. In Egypt, FMD virus serotypes O, A and SAT2 are circulating with endemic nature since 1950s, 2006 and 2012, respectively [2], [25]. Vaccination with good quality FMD vaccines with the specific FMDV serotype at the suitable time were applied for control of the disease and prevention of losses in the stock production [5], [16]. Improvement of FMD vaccine depends mainly on the selection of the proper adjuvant that can elaborate a high and long-lasting immunity as well as using the suitable antigen payload in vaccine formulation to obtain highly immunogenic vaccine [17]. Oil adjuvant vaccines were shown to induce higher antibody titers that persisted for longer time periods than that of aluminum hydroxid gel vaccines [11], these oil adjuvants should be of low viscosity to prevent undesirable side effects as granulomas and cysts [9]. Montanide oil adjuvants have many advantages including low viscosity, easy administration and greater stability, as well as it acts as a vehicle for transport of the antigen throughout the lymphatic system and slow antigen release with the stimulation of antibody producing plasma cells [5]. The present work was performed for preparation of an inactivated trivalent $\mathrm{FMD}$ vaccine $(\mathrm{O}, \mathrm{A}$ and
SAT2) adjuvant with Montanide ISA 201 and its evaluation through studying the humoral and cellular immune responses for vaccination in sheep.

\section{Materials and methods}

2.1 Foot and mouth disease (FMD) virus strains A tissue culture adapted FMD virus strains including $O$ pan asia, A/Iran 05 and SAT2/EGY/2012 of cattle origin, were obtained from Veterinary Serum and Vaccine Research Institute (VSVRI), Abassia, Cairo. FMD virus strains were typed and subtyped at the FMD Department, VSVRI, Abassia, Cairo and confirmed by the World Reference Laboratories, Pirbright, United Kingdom. The viral strains were stored at $70{ }^{\circ} \mathrm{C}$ and were used as seed virus for preparation of the vaccine and in Complement Fixation Test (CFT), Serum Neutralization Test (SNT), Enzyme Linked Immuno-Sorbent Assay (ELISA) and XTT assay.

2.2 Baby hamster kidney cell line (BHK21 clone 13) It was supplied by the Animal Research Institute, Pirbright, UK. It was propagated at FMD Department, VSVRI, Abbasia, Cairo, Egypt by using of minimum Essential Medium (MEM) with Eagle's salts and with $10 \%$ new born calf serum [21]. These cells were used for virus propagation, titration and SNT.

\subsection{Experimental Sheep}

A total number of 32 local breed sheep of about $35-50 \mathrm{~kg}$ body weight and 9 months age. They were clinically healthy and not vaccinated against FMD. The sheep were tested to be free from FMD 
antibodies by SNT and they were used for evaluation of the prepared inactivated vaccine.

\subsection{Vaccine formulation}

FMD virus strains were inoculated onto a monolayer BHK-21 cell line that harvested at over $70 \%$ cytopathic effect after $36 \mathrm{~h}$, then they were purified by centrifugation at $3000 \mathrm{rpm}$ for 20 minutes to remove cell debris [19]. The infectivity titer of the tissue culture adapted viruses were estimated on BHK21 cell line [24] and their antigenicity were titrated using Complement Fixation Test (CFT), [26]. The seed FMD virus strains had a titer of 108TCID50/ml and 64 using infectivity titration and CFT, respectively for each FMD virus strain. They were inactivated by a combination of Binary Ethyleneimine (BEI) $1 \mathrm{mM}$ and $0.04 \%$ formaldehyde [7] and the vaccine formulation was carried out where the oil phase consisted of Montanide ISA 201, mixed as equal parts of an aqueous and oil phase weight/ weight, and mixed to make water-in-oil-in-water suspension [5].

\subsection{Quality control of the prepared vaccine}

Sterility and safety were evaluated for the prepared inactivated trivalent FMD vaccine [10].

\subsection{Experimental design}

Sheep were used for evaluation of the prepared inactivated trivalent FMD vaccine with Montanide ISA201 adjuvant as follow:

Group (1): Twenty-five sheep vaccinated with $1.5 \mathrm{ml} / \mathrm{animal}(\mathrm{S} / \mathrm{C})$ of the prepared oil vaccine as one dose.

Group (2): Five sheep were kept as control without vaccination.

Group (3): Two sheep were used in safety test of the prepared vaccine.

Blood samples collected on heparin as anticoagulant for evaluation of cell- mediated immune response before and after vaccination (3rd, 7 th, 10th days and 2 weeks post vaccination then weekly till 9th week post vaccination. Serum samples from animals in groups (1) and (2) were collected before vaccination and weekly after vaccination for 40 weeks to measure the efficacy and duration of immunity in vaccinated sheep using SNT and ELISA.

\subsection{Cell proliferation XTT assay}

Growth and proliferation of lymphocyte was determined using Cell Proliferation Kit II (XTT) Colorimetric assay (XTT based) for the nonradioactive quantification of cell proliferation and viability according to the manufacturer instruction, Cat. No. 11465015001 (Roche Applied Science, Mannheim, Germany).
2.8 Serum neutralization test (SNT)

SNT was performed using the micro-technique to detect serum neutralizing antibodies against FMD virus serotypes $\mathrm{O}, \mathrm{A}$ and SAT2. The antibody titer was estimated as the reciprocal of the final serum dilution which neutralized and inhibited the CPE of 100 TCID $_{50}$ of FMD virus serotypes O, A and SAT2 [14].

\subsection{Enzyme Linked Immunosorbent Assay (ELISA)}

FMD virus serotypes $\mathrm{O}, \mathrm{A}$ and SAT2 antigens were prepared from infected BHK -21 cells and concentrated by PEG (6000) according to [28], then used in ELISA to estimate the specific antibodies of different serotypes of FMD virus [27].

\section{Results}

\subsection{Sterility and safety of the vaccine}

The prepared vaccine was free from aerobic and anaerobic bacteria and fungi. It was also safe and gave satisfactory results indicated by absence of cytopathic effect on tissue culture, and absence of local and systemic reactions on inoculated sheep with no rise in body temperature.

\subsection{Humeral immune response}

Evaluation of humeral immune response of sheep vaccinated with inactivated trivalent FMD vaccine adjuvant on montanide ISA 201 using SNT showed that protective neutralizing antibody titer (1.5) for FMD virus serotypes O, A and SAT2 started from the second wPV, reached the highest level at $12^{\text {th }} \mathrm{wPV}$ and persisted in protective level until $40^{\text {th }}$ wPV. These results compared to the nonvaccinated sheep (control group) was shown in table (1) and Fig (1). Humeral immune response of vaccinated sheep evaluated using ELISA showed that antibody titers for FMD virus serotypes $\mathrm{O}, \mathrm{A}$ and SAT2 started to increase from the first wPV, reached the highest level at $12^{\text {th }} \mathrm{wPV}$ and persisted in positive level until $40^{\text {th }} \mathrm{wPV}$. These results compared to the control group was shown in table (2) and Fig (2).

\subsection{Cell mediated immune response}

Evaluation of FMD virus-specific cell-mediated immunity in sheep vaccinated with FMD vaccine adjuvanted with Montanide ISA 201 oil adjuvant was performed using lymphocyte proliferation XTT assay showed increase in optical density of proliferated lymphocyte in vaccinated sheep from the $3^{\text {rd }}$ day post vaccination (dPV), increased to reach a maximum value $2^{\text {nd }}$ wPV and persisted in a high level till $9^{\text {th }}$ wPV for FMD virus serotypes O, $A$ and SAT2 inducers, compared with that of control non-vaccinated sheep group that had no lymphocyte proliferation against FMD virus as shown in table (3) and fig (3). 
Table (1) Mean neutralizing antibody titers against FMD virus serotypes O, A and SAT2 in sera of vaccinated sheep with inactivated trivalent FMD vaccine using SNT.

\begin{tabular}{lcccccc}
\hline Weeks & \multicolumn{6}{c}{ Mean $\log _{\mathbf{1 0}}$ neutralizing antibody titers } \\
\cline { 2 - 7 } Post & \multicolumn{2}{c}{ Serotype $\mathbf{O}$} & \multicolumn{2}{c}{ Serotype A } & \multicolumn{2}{c}{ Serype SAT2 } \\
\cline { 2 - 7 } Vacc. & Vaccinated & Control & Vaccinated & Control & Vaccinated & Control \\
\hline 0 & 0.33 & 0.32 & 0.34 & 0.32 & 0.28 & 0.32 \\
1 & 1.30 & 0.32 & 1.27 & 0.32 & 1.32 & 0.32 \\
2 & 1.73 & 0.36 & 1.73 & 0.36 & 1.65 & 0.36 \\
3 & 1.98 & 0.36 & 1.97 & 0.36 & 2.05 & 0.36 \\
4 & 2.30 & 0.35 & 2.27 & 0.35 & 2.32 & 0.35 \\
6 & 2.60 & 0.35 & 2.56 & 0.35 & 2.60 & 0.35 \\
8 & 2.80 & 0.39 & 2.78 & 0.39 & 2.81 & 0.39 \\
10 & 2.90 & 0.39 & 2.89 & 0.39 & 2.92 & 0.39 \\
12 & 3.10 & 0.35 & 3.09 & 0.35 & 3.11 & 0.35 \\
14 & 2.85 & 0.39 & 2.99 & 0.39 & 2.98 & 0.39 \\
16 & 2.69 & 0.32 & 2.81 & 0.32 & 2.83 & 0.32 \\
18 & 2.58 & 0.30 & 2.64 & 0.30 & 2.62 & 0.30 \\
20 & 2.38 & 0.32 & 2.45 & 0.32 & 2.46 & 0.32 \\
24 & 2.24 & 0.30 & 2.29 & 0.30 & 2.32 & 0.30 \\
28 & 2.05 & 0.31 & 2.09 & 0.31 & 2.14 & 0.31 \\
32 & 1.85 & 0.30 & 1.88 & 0.30 & 1.90 & 0.30 \\
36 & 1.67 & 0.30 & 1.69 & 0.30 & 1.67 & 0.30 \\
24 & 1.45 & 0.30 & 1.48 & 0.30 & 1.52 & 0.30 \\
\hline
\end{tabular}

Protective serum neutralizing antibody titer $=1.5 \log 10$ according to OIE (2012) Values calculated as geometric mean.

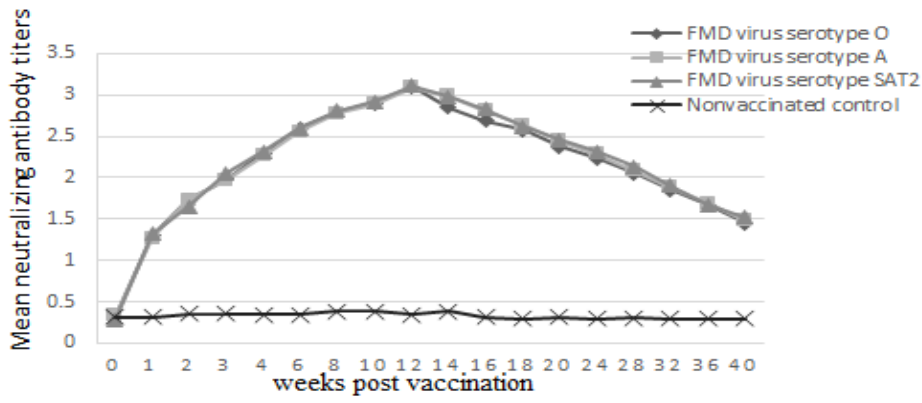

Fig (1) Duration of neutralizing antibody titers against FMD virus serotypes $\mathrm{O}$, A and SAT2 in sera of vaccinated sheep with inactivated trivalent FMD vaccine.

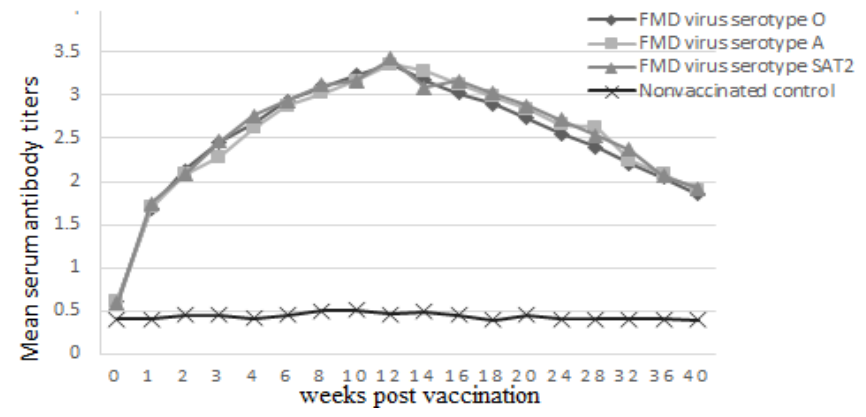

Fig (2) Duration of antibody titers against FMD virus serotypes O, A and SAT2 in sera of vaccinated sheep with inactivated trivalent FMD vaccine using ELISA. 
Table (2) Mean antibody titers against FMD virus serotypes O, A and SAT2 in sera of vaccinated sheep with inactivated trivalent FMD vaccine using ELISA.

\begin{tabular}{ccccccc}
\hline \multirow{2}{*}{$\begin{array}{c}\text { Weeks } \\
\text { Post }\end{array}$} & \multicolumn{5}{c}{ Mean $\log _{\mathbf{1 0}}$ Serum antibody titers } \\
\cline { 2 - 7 } Vacc. & \multicolumn{2}{c}{ Serotype O } & \multicolumn{2}{c}{ Serotype A } & \multicolumn{2}{c}{ Serotype SAT2 } \\
\cline { 2 - 6 } Vaccinated & Control & Vaccinated & Control & Vaccinated & Control \\
\hline 0 & 0.62 & 0.41 & 0.61 & 0.41 & 0.59 & 0.41 \\
1 & 1.69 & 0.41 & 1.70 & 0.41 & 1.75 & 0.41 \\
2 & 2.13 & 0.45 & 2.08 & 0.45 & 2.08 & 0.45 \\
3 & 2.46 & 0.45 & 2.28 & 0.45 & 2.47 & 0.45 \\
4 & 2.67 & 0.42 & 2.62 & 0.42 & 2.76 & 0.42 \\
6 & 2.94 & 0.45 & 2.88 & 0.45 & 2.94 & 0.45 \\
8 & 3.10 & 0.50 & 3.02 & 0.50 & 3.12 & 0.50 \\
10 & 3.23 & 0.51 & 3.17 & 0.51 & 3.17 & 0.51 \\
12 & 3.37 & 0.46 & 3.36 & 0.46 & 3.42 & 0.46 \\
14 & 3.18 & 0.49 & 3.28 & 0.49 & 3.09 & 0.49 \\
16 & 3.02 & 0.45 & 3.13 & 0.45 & 3.17 & 0.45 \\
18 & 2.90 & 0.40 & 2.98 & 0.40 & 3.02 & 0.40 \\
20 & 2.73 & 0.45 & 2.84 & 0.45 & 2.88 & 0.45 \\
24 & 2.55 & 0.41 & 2.66 & 0.41 & 2.72 & 0.41 \\
28 & 2.40 & 0.41 & 2.63 & 0.41 & 2.53 & 0.41 \\
32 & 2.21 & 0.41 & 2.25 & 0.41 & 2.37 & 0.41 \\
36 & 2.04 & 0.41 & 2.08 & 0.41 & 2.06 & 0.41 \\
24 & 1.85 & 0.40 & 1.90 & 0.40 & 1.92 & 0.40 \\
\hline
\end{tabular}

Values calculated as geometric mean.

Table (3) Mean delta optical density of lymphocyte proliferation of sheep vaccinated with inactivated trivalent FMD vaccine adjuvant with montanide oil ISA 201 using XTT assay.

\begin{tabular}{lcccc}
\hline Time & \multicolumn{4}{c}{ Mean delta optical density of lymphocyte proliferation against FMD virus } \\
\cline { 2 - 4 } Post vacc. & Serotype & Serotype & Serotype SAT2 & Control \\
\hline 0 & 0.048 & 0.050 & 0.050 & 0.052 \\
3dpv & 0.517 & 0.504 & 0.517 & 0.051 \\
7dpv & 0.863 & 0.832 & 0.870 & 0.052 \\
10dpv & 1.691 & 1.460 & 1.585 & 0.052 \\
2wpv & 2.018 & 1.958 & 1.999 & 0.052 \\
3wpv & 1.658 & 1.617 & 1.688 & 0.052 \\
4wpv & 1.453 & 1.380 & 1.477 & 0.052 \\
5wpv & 0.940 & 1.006 & 1.023 & 0.052 \\
6wpv & 0.828 & 0.894 & 0.889 & 0.052 \\
7wpv & 0.823 & 0.816 & 0.828 & 0.052 \\
8wpv & 0.767 & 0.713 & 0.762 & 0.052 \\
9 wpv & 0.048 & 0.050 & 0.050 & 0.052 \\
\hline
\end{tabular}

Values calculated as geometric mean.

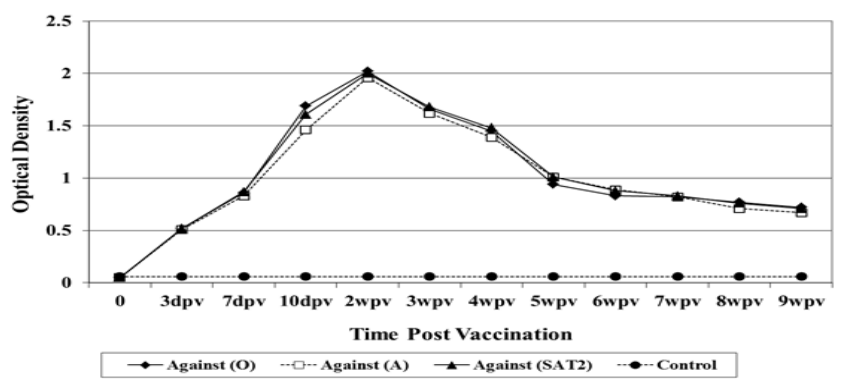

Fig (3) Duration of lymphocyte proliferation of sheep vaccinated with inactivated trivalent FMD vaccine adjuvant with montanide oil ISA 201 expressed as delta optical density using XTT assay. 


\section{Discussion}

The prepared tissue culture adapted inactivated FMD virus trivalent vaccine was inoculated on BHK cell line without appearance of any CPE indicating no viable viral residues. This agreed with the study stated that there are three important factors essential to produce FMD vaccine including viral propagation for large scale production, virus inactivation without residual infectivity remains and addition of a non-toxic adjuvant to enhance the immune response to a satisfactory level [12].

A trivalent inactivated FMD vaccine was formulated using ISA 201 as adjuvant from FMD virus serotypes (O/pan Asia, A/Iran 05, SAT2/EGY/2012) after their purification and concentration and inactivation (each dose of vaccine contains not less than $10^{8} \mathrm{TCID}_{50} /$ dose for each FMD virus strain), [5]; each prepared vaccine was tested for its sterility and purity from any bacterial or fungal contaminants on Tryptose phosphate broth, Thioglcolate broth, Sabouraud's agar and mycoplasma medium [10]. It was noticed that all vaccinated animals did not show any FMD clinical signs post vaccination indicating the safety of local inactivated trivalent FMD vaccine adjuvanted with Montanide ISA 201 oil adjuvant.

Evaluation of humeral immune response of sheep vaccinated with inactivated trivalent FMD vaccine adjuvant on montanide ISA 201 using SNT showed that protective neutralizing antibody titer (1.5) for FMD virus serotypes O, A and SAT2 started from the second week post vaccination (wPV), reached the highest level at $12^{\text {th }} \mathrm{wPV}$ and persisted in protective level until $40^{\text {th }} w P V$. These results compared to the control group was shown in table (1) and fig (1) and agreed with findings of the studies proved good humoral immune response of cattle to oil adjuvant inactivated FMD vaccines evaluated using SNT [1], [15]. Evaluation of humeral immune response in sheep vaccinated with inactivated trivalent FMD vaccine adjuvant on montanide ISA 201 using ELISA for FMD virus serotypes O, A and SAT2 showed that antibody titer started to increase from the first wPV, reached the highest level at $12^{\text {th }} \mathrm{wPV}$ and persisted in positive level until $40^{\text {th }}$ wPV. These results compared to the control group was shown in table (2) and fig (2). These results confirmed the results of SNT. These findings agree with the studies proved good humoral immune response of cattle to oil adjuvant inactivated FMD vaccines evaluated using ELISA [4], [8], [23].

Evaluation of FMD virus-specific cell-mediated immunity in sheep vaccinated with FMD vaccine adjuvanted with Montanide ISA 201 oil adjuvant was performed using lymphocyte proliferation XTT assay showed significant lymphocyte proliferation expressed by optical density in vaccinated sheep group from the $3^{\text {rd }}$ day post vaccination (dPV), increased to reach a maximum value $2^{\text {nd }} \mathrm{WPV}$ and persisted in a high level till $9^{\text {th }}$ wPV for FMD virus types O, A and SAT2 inducers, compared with that of control non-vaccinated sheep group that had no lymphocyte proliferation against FMD virus as shown in table (3) and Fig (3). These results came in agreement with studies showed highest delta optical density level for ISA 201 on 14 and 21 days post vaccination (DPV) [18]. Also, these results agreed with the studies stated that an adjuvant acts in one or more of five ways, based on current knowledge; namely, immune-modulation, presentation, induction of cytotoxic T-lymphocyte (CTL) responses, targeting, and depot generation. Addition to that adjuvant plays an important role in production of different lymphokines such as various interleukins and interferon gamma [6], [13].

\section{Conclusion}

The prepared inactivated trivalent FMD vaccine with ISA-201 adjuvant can stimulate a good humoral and cellular immune responses in vaccinated sheep started from the $2^{\text {nd }}$ wPV and lasted for $40 \mathrm{wPV}$.

\section{References}

[1]A.O.Abd El-Rahman, A.M.H.Azab, A.M.Aggour, F.A.A.Moussa, M.Abo ElYazeid, Studies on cellular and humeral immune response in cattle against FMD bivalent vaccine. J. Egypt, Assuit Veterinary Medicine, vol. 67, no. 2, pp. 265-272, 2007.

[2] A.O.Abd El-Rahman, M.A.Farag, S.El-Kilany, S.M.Ali, M.Abo El-Yazed, Isolation and identification of Serotype O of Foot and Mouth Disease virus from imported Bulls and its correlation to the current used vaccine strain $\mathrm{O}_{1} / 3 / 1993$, Proc. $3^{\text {rd }}$ Inter Conf. Vet. Res. Div., NRC, Cairo, Egypt, pp. 91-100, 2006.

[3] N.Aggarwal, Z. Zhang, S. Cox, R. Staatham, S. Alexandersen, R.P.Kitching, P.V. Barnett, 
Experimental studies with foot and mouth disease virus, strain $(\mathrm{O})$ responsible for the 2001 epidemic in the United Kingdom, Vaccine, vol. 20, pp. 2508-2515, 2002.

[4] A.L.Barnard, A.Arriens, S.Cox, P.Barnett, B.Kristensen, A.Summerfi, K.C.McCullough, Immune response characteristics following emergency vaccination of Pigs against FMD, Vaccine, vol. 23, no. 8, pp. 1037-1047, 2005.

[5] P.Barnett, L.Pullen, L.Williams, T.R.Doel, Assessment of Montanide ISA 25 and ISA 206, two commercially available oil adjuvant, Vaccine, vol. 14, no. 13, pp. 1187-1198, 1996.

[6] P.V.Barnett, P.Keel, S.Reid,, R.M.Armstrong, R.J.Statham, C.Voyce, N.Aggarwal, , S.J.Cox, Evidence that high potency foot and mouth disease vaccine inhibits local virus replication and prevents the 'carrier' state in sheep, Vaccine, vol. 22, pp.1221-1232, 2004.

[7] S.J.Barteling, N.I.Cassim, Very fast (and safe) inactivation of FMD virus and enteroiruses by a combination of binary ethylenimine and formaldehyde. Schudel, A., Lombard, M. editors. Control of Infections Animal Disease by Vaccination. Vol. 119. Kager, Basel. Pp. 449-455, 2004.

[8] J.Bayry, K.Prabhudas, S.Gopalakrishna, P.K.Patil, C.Ramakrishna, L.D.Mishra, V.V.S.Suryanarayana, Protective immune response to $16 \mathrm{kDa}$ immunoreactive recombinant protein encoding the $\mathrm{C}$-terminal VP1 portion of Foot and Mouth Disease Virus type Asia I, Microbiol. Immunol., vol. 43, pp. 768-771, 1999.

[9] R.Bomford, Adjuvants in veterinary vaccines In: Mowat, N., Rweyemamu, M., editors, Vaccine Manual: The Production and Quality Control of Veterinary Vaccines for Use in Developing Countries. FAO, Rome, p277-284, 1997.

[10] Code of Federal Regulation of USA (CFR), Published by the office of the federal register national archives and Record administration, Animal and animal products 9\1986, 1986.

[11] R.Cunliffe, J.H.Graves, Formalin treated FMDV comparison of two adjuvants in cattle, J. Comp. Vet. Sci., vol. 27, pp. 193-197, 1963.

[12] W.Deghaidy, A.Daoud, A.El-Molla, Immune response of sheep to foot and mouth disease vaccines containing different adjuvants, Small Ruminant Research, vol. 45, pp.185-192, 2002.

[13] M.Ebeid, F.K.Hamouda, M.Farag, S.E.Mahdy, Detection of sub-clinical cases in emergency vaccinated animals after challenged with foot and mouth disease virus, Benha Veterinary Medical Journal, special issue [ii], 4th Sci. Conf., Al-Kasr 25-28 May, 2011, Fac. Vet. Med., Benha University, Egypt, 2011.

[14] M.E.V.Ferreira, Prubade microneutralization poraestudies de anticueropos de la fibre aftosa, 13th Centropanamericano Fibre aftosa, vol. 21/22, pp.17-24, 1976.

[15] H.El-Watany; M.Shawky, O.H.Roshdy, S.ElKilany, Relationship between cellular and humeral immune response in animals vaccinated with FMD vaccine, J. Egypt, Zagazig Veterinary Medicine, vol. 27, no. 1, pp. 137-143, 1999.

[16] P.Hunter, Vaccination as a means of control of foot-and-mouth disease in sub-saharan Africa, Vaccine, vol. 16, no. 2, pp. 261-264, 1997.

[17] E.E.Ibrahim, Advanced studies on Foot and Mouth Disease Vaccines of sheep in Egypt. $\mathrm{PhD}$.Sc. Thesis (Infectious Diseases), Faculty of Veterinary Medicine, Cairo University, Egypt, 2011.

[18] E.E.Ibrahim, W.M.Gamal, A.I.Hassan, S.E.Mahdy, A.Z.Hegazy, M.M.Abdel-Atty, Comparative study on the immunopotentiator effect of ISA 201, ISA 61, ISA 50, ISA 206 used in trivalent foot and mouth disease vaccine, Veterinary World, vol. 8, no. 10, pp.1189-1198, 2015.

[19] R.A.Killington, A.Stokes, Hierolzer, Virology methods manual, Chapter 4: pp. 72-89, 1996.

[20] N.Longjam, R.Deb, A.K.Sarmah, T.Tayo, V.B.Awachat, V.K.Saxena, A brief review on diagnosis of foot-and-mouth disease of livestock: conventional to molecular tools. Veterinary Medicine International, Article ID 905768. https://doi.org/10.4061/2011/905768, 2011.

[21] M.Macpherson, B.Stocker, Polyma transformation hamster cell clones, an investigation of genetic factors affecting cell competence, Virology, vol. 16, pp. 147-51, 1962.

[22] OIE, Manual of diagnostic tests and vaccines for terrestrial animals, Chapter 2.1.5, http://www.oie.int/en/internationalstandard-setting/terrestrial-manual/accessonline, 2012.

[23] P.K.Patil, J.Bayry, C.Ramakrishna, B.Hugar, L.D.Misra, C.Natarajan, Immune response of goats against FMD quadrivalent vaccine: comparison of double oil emulsion and aluminum hydroxide gel vaccine in eliciting 
immunity, Vaccine, vol. 20, pp. 2781-2789, 2002.

[24] L.J.Reed, H.Muench, A simple method for estimating fifty percent (50\%) end points, Amer. J. Hyg., vol. 27, pp. 493-497, 1938.

[25] M.Shawky, , M.Abd El-Aty, M.F.Hiam, M.D.Hind, E.I.Ehab, M.G.Wael, A.R.Sonia, H.Abu-Elnaga, A.A.Mohamed, A.Abd Elkreem, E.M.Farouk, Isolation and Molecular Characterization of Foot and Mouth Disease SAT2 Virus during Outbreak 2012 in Egypt, Journal of Veterinary Advances, vol. 3, pp.6068

https://doi.org/10.5455/jva.20130219104353, 2013.

[26] E.Traub, I.R.Manso, Uber die herstellung complement bindender merrsch-weinehon sera fur die typendiagnose bie Maul und Klauenseuche.Zbi. Bakt. Lorig., vol. 151, pp.380-381, 1944.

[27] A.Voller, D.E.Bidwell, A.Bartlett, Microplate enzyme immunoassays for the immunodiagnosis of virus infections, In Manual of Clinical Immunology, Chapter 69, edited by N. Rose and H. Friedman, pp. 506512, American Society for Microbiology, 1976.

[28] G.G.Wagner, J.L.Card, K.M.Cowan, Immunochemical studies of foot-and-mouth disease, VII. Characterization of foot-andmouth disease virus concentrated by polyethylene glycol precipitation, Arch. Ges. Virusforsch., vol. 30, pp. 343-352, 1970. 